Volume 10, No.2, March - April 2021

International Journal of Advanced Trends in Computer Science and Engineering

Available Online at http://www.warse.org/IJATCSE/static/pdf/file/ijatcse1331022021.pdf

https://doi.org/10.30534/ijatcse/2021/1331022021

\title{
Impact of Occupational Health \& Safety Management on Risk Existing At Construction Sites of Karachi
}

\author{
Abdul Majeed Pirzada ${ }^{1}$, Faris Mahar $^{2}$, Aamir Iqbal Umrani ${ }^{3}$, Asif Ali Wagan ${ }^{4}$, Muhammad Amin Qureshi $^{5}$, \\ Muhammad Mohsin Khan ${ }^{6}$, Naeem Akhtar Samoon ${ }^{7}$ \\ ${ }^{1}$ Department of Environmental Sciences, Sindh Madressatul Islam University, Pakistan, ampirzada@smiu.edu.pk \\ ${ }^{2}$ Department of Business Administration, Sindh Madressatul Islam University, Pakistan \\ ${ }^{3}$ Department of Business Administration, Sindh Madressatul Islam Uinversity, Pakistan \\ ${ }^{4}$ Department of Computer Sciences, Sindh Madressatul Islam University, Pakistan \\ ${ }^{5}$ Department of Agriculture Extension Jamshoro, Sindh, Pakistan \\ ${ }^{6}$ Department of Environmental Sciences, Sindh Madressatul Islam University, Pakistan \\ ${ }^{7}$ Department of Environmental Sciences, Sindh Madressatul Islam University, Pakistan
}

\begin{abstract}
The assessment of OHSM is the most crucial element in a Pakistani construction industry. In Pakistan, the industry related to the construction is the biggest industry as compared to another industry and it is considered as the industry containing the greater number of hazards. This quantitative study reveals that the negative relationship between occupational health and safety management and risk exists at the construction site. This research paper is aimed at evaluating and examining the health and safety administration framework present in different firms operating in the construction sector of Karachi and suggests the measures to promote and effectively employ the usage of work-related safety and health administration framework in the construction firms located in Karachi. An observational examination was embraced to recognize the related health and safety in different construction industries in
\end{abstract}

\section{INTRODUCTION}

The construction sector is one of those sectors where accidents are recorded with greater figures which result a highly preventable cost [24]. The construction industry of Pakistan is the highly growing industry. The management's communication, approach and the support were the most imperative predictors of safe environment in the construction industry. The informal sector requires facilities drastically regarding health and safety which makes this sector evidencing the significant number of accidents at the sites of construction. The majority of the workers in construction industry are posted at the informal
Karachi. Review information was gathered from eight different construction industries of Karachi, Pakistan, through interview and physical survey. The collected data was analyzed by utilizing SPSS software. The regression and Pearson correlation analysis were used for an assessment of relation between OHSM \& risk. Results revealed that the health and safety condition of Construction industries of Karachi were not met with national and international health and safety legal, laws and policies. This reflects that the system regarding OHSM were not legitimately completed. Along these lines, Pakistani Construction industries need to give careful consideration towards appropriate execution of health and safety management (OHSM) system.

Key words: Occupational Health \& Safety Management (OHSM), Risk, Construction, Risk Assessment, SPSS.

construction places in Pakistan [13]. Pakistan is still lacking in skilled and qualified persons and institutions for providing efficient occupational health and safety services. The idea regarding the OHSM at the workplace is has not yet matured in Pakistan hence resulting in the increase in the rate of fatality. Ninety percent of the participants are working in the hot environment especially in the construction industry of Pakistan $s$ [3]. In accordance with the facts and figures of the survey conducted in the year 2007, in contracting firms, most of the injuries occur at the site project are falling injuries, heatstroke, head injuries, eye injuries, burning injuries, and injuries by wastage 
and raw materials. Lack of using PPE'S, scaffolding safety and access of height is other major causes of incidents. Unskilled workers, no job understanding $\&$ the lack of knowledge, poorly maintaining of the equipments, electrocution, and use of alcohol or drugs are the major cause of accidents [21]. In 2001, Government of Pakistan established a council for Labors named as National Occupational Health, Safety Council (NOHSC) which was responsible to review and update the laws of health and safety related to the occupation as per requirements of international laws and standards. Pakistan is still losing billions in International trade because of the negligence of OHSM rules and regulations. Pakistan has more fatal occupational accidents because of the inferior working environment. Most of the laborers working in Pakistan belong to unskilled workers. In Pakistan, the huge number of uneducated workers is unofficially employed in the construction industry [12]. Pakistan is reported as a country evidencing a huge number of accidents occurring at the construction industry due to direct exposure of workers with the hazardous materials present the site of construction. Besides that, the other reasons are also evidenced because workers behave casually at their workplaces keeping no care of safety protocols, rules and regulations. The framework regarding the present conditions of OHS in the Pakistani construction sector is still uneven and not efficiently implemented which makes the sites of the construction as a dangerous place. It can be said that appropriate policy is not relevant and has not been updated too for carrying out construction operations on regular basis. The largely informal construction sector is still lacking in the safeguard which is available for industrial workers because most of the labor laws have no relation with this sector and the rate of injuries and accidents is greater. Brick kiln labors are spread across Pakistan. According to labor department sources in Punjab province, has got 500 registered brick kiln as measured against 1,900 unregistered. The total quantity of people working was found to be more than 100,000. The statistics showed that the brick dust becomes the reason for eye allergies, lung infections, depressions, backache, and skin diseases [26]. According to SMEDA, 90\% of establishments are small enterprises and contribute $40 \%$ of the Gross Domestic Product (GDP). Mostly 90-95\% of SMEs fail due to its competitive conditions. In this situation, OHS performs the essential role in the long-term survival of Pakistani SMEs. SMEs of Pakistan fail to implement the occupational health and safety in their premises. Working deaths in Pakistan are higher as compared with other developing countries, around 7444 death accidents 5,680,740 occupational accidents occurred annually. Workplace hazards in SMEs are higher than large enterprises.

Certain premises have their particular hazards that will need to be addressed, the host organization and the contractors will need to manage the risks created by their own work and cooperate closely to manage those risks created in the workplace. The health and safety conditions in the different industries are very different, deaths and injuries take a predominantly serious incriminate in Pakistan, where a large part of the population is occupied in hazardous activities such as in the construction industry. It is very important that construction work is habitually called high risk when they are high hazard. The OHS creates an impact on all aspects of the work. In an organization with low hazards, health and safety can be monitored by a single knowledgeable supervisor. In the manufacturing plant with the high hazard, various specialists such as work planners, supervisors, and engineers, may be needed to ensure the health and safety standards contained by the firm. The demands of manufacturing or performance targets, financial constraints and the complexity of organizational structure are considered as the typical examples. There are some dominant incentives for organizations, these incentives are economic, legal and moral [18].

Peoples' participation, emergency preparedness, safety observation, risk, training, accident experience, employee commitment, safety compliance, stress, teamwork and reporting incident give the positive outcome in the industry such as such, as good attitude, satisfaction of a job, higher motivation, workforce morale enhancement. The productivity of industry based on good working environment, good material, quality of product, compensation cost, reputation, increase the working ratio, customer perception, and rate of accidents in industry (Thanwadee, Supatana \& Suthaporn, 2011)

\section{LITERATURE REVIEW}

The study conducted by (Raj et al) assesses the role of the OHS Assessment Series (OHSAS18001) indicated in affirmed organizations in Iran. This investigation assesses the viability of Occupational Health Safety Management System by studying six 
organizations in Iran that are engaged with extensive scale modern activities, for example, the plan and development. Three of the organizations were OHSAS 18001 certified, and the other three were most certainly not. The three ensured organizations had no less than 3 years' involvement of health and safety administration. Study shows that the execution of ensured organizations as for word related occupational health and safety administration rehearses is essentially superior to anything that of non-certified industries (Raj et al, 2017). The research was conducted on the existing position of Occupational Health and Safety (OHS) related practices in the unceremonious construction sector of Pakistan [13]. Data was collected, during interviews, from 316 construction sites employing 3577 workers. The results of the study revealed that both employers and workers have lack of knowledge regarding Occupational Health and Safety (OHS) laws and no practice ensuring health and safety is implemented at sites where construction is going on. The informal sector of construction employs the huge segment of informal labor force, and lack of OHS practices bring about an incredible human cost [13]. The study was conducted to review hazards faced by elementary workers [3]. For this intention, questionnaire surveys and respiratory purpose test (spirometry) were carried out on 150 respondents. Major hazards and risk identified with sharp protests, overwhelming weightlifting, thermally cruel conditions, working at stature, entire body vibration, synthetic compounds, pathogens, expanded commotion levels and bound space section. Laborers experienced upper and lower respiratory confusion indications, stomach related issues, optical and musculoskeletal issues, and so on. Spiro metric estimation demonstrated obstructive lung issue to be most elevated among development and Specialists which was $48 \%$ remaining. This examination demonstrates that word related introduction can essentially impact respiratory framework disability. The investigation suggests the utilization of proper defensive hardware and customary medicinal examination for early acknowledgment of any health hazard [3]. The study was conducted to find out the connection between word related occupational health and safety measures (OHSMs) and execution of little and medium size enterprises (SMEs). The result of this study shows that the short and medium enterprises or industries in Pakistan are not implementing the Occupational health and safety rules and regulations, and Pakistan should implement the Occupational health and safety measures to minimize the rate of occupational accidents and incidents, because it can affect the negative impacts on the economy of Pakistan [18]. Another research presents an approach to identify critical exposure levels or heath-based benchmarks of employment control [23]. This strategy gives benchmarks to chance appraisal of psychosocial dangers, like benchmarks utilized for other word related health risks, for example, synthetics. Depression is a more sensitive (health comprising) result for work control [23]. The research study assesses the expository relations among the moral thinking, proficient duty and the administrative consistence conviction among business and representatives. By watching the investigation, important boss will be skilled to focus on likely regions of basic contained by security necessities adequate to well define and inevitable health and safety requirements in Malaysia. Ethical reasoning, regulatory compliance and commitment endure the claims of industry [22]. Study in the construction industry was conducted with the help of an Occupational risk assessment (ORA) on workplace sites. It is the first and key advance to accomplish sufficient safety levels, especially to help basic leadership in safety programs. Most development safety endeavors are connected casually under the start that essentially designating more assets to safety g administration will enhance safety on location [1]. Also, there are numerous customary strategies to address ORA, yet few have been adjusted and approved for use in the development business, especially in the outline arrange, for which conventional methodologies don't give satisfactory answers [1]. 58\% firms follow the OHSAS 18001 standard and $42 \%$ are not following the OHSAS 18001 standard as well as they have not the proper documentation of OHSAS 18001.By the implementation of OHSAS 18001 in the company accidents has been significantly reduced and cost of system implementation significantly reduced by $40 \%$ in three years [25].

\section{METHODOLOGY}

This study was led through a survey randomly at eight construction firms located in Karachi. Unit of analysis was construction industries, based on the fact that they were found engaged in construction activities at the time of the survey. Our research consists of four stages. The first stage includes the preparation of a questionnaire; secondly risk 
assessment at the workplace was done by visiting different sites. Thirdly the data on the questionnaire was collected from respondents and finally the results from the survey and risk assessment of the workplace at the construction site were analyzed. The results obtained from questionnaire were analyzed using SPSS 16 . The descriptive statistics $\&$ reliability analysis were run on SPSS. The risk assessment was done with the help of the formula:

$\operatorname{Risk}(\mathrm{R})=\operatorname{Likelihood}(\mathrm{L}) *$ Consequences $(\mathrm{C})$

For conducting this study, a questionnaire was developed in accordance with the principles of Occupational Health and Safety Assessment Series (OHSAS 18001) [20]. The questionnaire was circulated among the respondents and each of the respondents was comprised of an employee of the construction firms. Employees of various firms were asked to fill up the questionnaire, but the rate of response varied from Industry to Industry. In some industries the respondents were 35,40 , and 45 and in some, there were $42,47,38,41$ and 49. The questionnaire consisting of 20 items which measured the occupational health and safety management in the workplace and the item was made dichotomous in response which means that respondent was supposed to choose any one option out of two. The responses for each item were yes and No. The values were assigned to each response yes was coded with ' 5 ' and No was coded ' 0 '. After administering the survey, the descriptive statistics were run on the SPSS. The mean values of each company were then assessed based on giving scale: $0-59 \%$ as Poor, $60-69 \%$ as fair, $70-79 \%$ as well, $80-89 \%$ as very good, and $90-100 \%$ as excellent. The questionnaire designing was then followed by the risk assessment of health and safety workplace hazards. This was done with the help of the formula used to calculate risk by multiplying the probability with consequence. The probability basically tells about the chances of hazardous events to occur and consequence is the outcome of the hazardous event. The estimation of risk factors involved the use of five-point (5 x 5) risk matrix which is used to rate the probability and consequence as per the standard quantitative and qualitative analysis of risk (IOSH). The action to each level of risk was assigned (Boyle, 2015). The activity levels of risks were unacceptable, Tolerable, Adequate and Acceptable and the ranges for rating were (17-25), (10-16), (5-9) and (1-4) respectively.

\section{RESULTS AND DISCUSSION}

If we compare the status in every industry, we will find that Men will be in the large quantity as compared to female. Table 1 shows that the collected data reconciles with the statement by stating the percentage of male and female workers. Company-1 constitutes $94 \%$ males and females constitute $6 \%$ of the site. In the construction company Company-5 the men constitute $86 \%$ male and female constitute $9 \%$ and remaining construction industries the quantity of female observed zero.

Table 1: Gender

\begin{tabular}{|l|c|c|}
\hline \multicolumn{1}{|c|}{ Company } & Male \% & Female \% \\
\hline Company-1 & 94 & 6 \\
\hline Company-2 & 100 & 0 \\
\hline Company-3 & 100 & 0 \\
\hline Company-4 & 100 & 0 \\
\hline Company-5 & 86 & 9 \\
\hline Company-6 & 100 & 0 \\
\hline Company-7 & 100 & 0 \\
\hline Company-8 & 100 & 0 \\
\hline
\end{tabular}

During a survey of different construction sites, it was observed that most of the workers were illiterate, having low level of experience and were lacking in basic knowledge of health and safety issues. The average experience of different construction industries was observed to be in between 1 and 15 years. The data collected from the field survey indicated that most of the people working in these companies were illiterate or having lower educational degree while very few of them having the higher education degrees. The working years of operations of different industries are different. The average working operations of construction companies is $10-20$ years as shown in Table 2

Table 2: Working Operations

\begin{tabular}{|c|c|}
\hline Working Operation & Years of Operation \\
\hline Company-1 & 15 Years \\
\hline Company-2 & 23 Years \\
\hline Company-3 & 13 Years \\
\hline Company-4 & 10 Years \\
\hline Company-5 & 18 Years \\
\hline Company-6 & 25 Years \\
\hline Company-7 & 08 Years \\
\hline Company-8 & 20 Years \\
\hline
\end{tabular}




\subsection{Occupational Health \& Safety Management in Construction Industry}

A questionnaire was consisting of 20 items and provided to the respondents of an individual construction companies. Dichotomous responses were assigned to each item and respondents answered them in Yes or No. The descriptive analysis was performed by using SPSS which involved the calculation of mean and standard deviations as shown in Table 3.

Table 3: OHSM Mean \& Standard Deviation

\begin{tabular}{|l|c|c|}
\hline \multicolumn{1}{|c|}{ Companies } & Mean \% & $\begin{array}{c}\text { Standard } \\
\text { Deviation }\end{array}$ \\
\hline Company-1 & 54 & 0.455 \\
\hline Company-2 & 46.42 & 0.402 \\
\hline Company-3 & 58.14 & 0.208 \\
\hline Company-4 & 52.85 & 0.397 \\
\hline Company-5 & 53.57 & 0.491 \\
\hline Company-6 & 51 & 0.464 \\
\hline Company-7 & 45 & 0.468 \\
\hline Company-8 & 48.14 & 0.44 \\
\hline
\end{tabular}

The mean of these 20 items was calculated for each company, hence making each company total mean as a single observation. The mean value of all the construction firms relies on the poor conditions which are unacceptable according to the OHS management assessment scale as mentioned above. The mean value of the company 1 is $54 \%$ because, during the survey it was found that the company 1 has not followed the OHSAS guidelines and lacking in proper arrangement for the workers at the construction site.

The mean value of second construction firm is $46.42 \%$ which is the poor safety management system and lack in safety trainings and possess unsafe working conditions. The mean value of the third construction firm comes out to be $58.14 \%$ which is the highest mean value as compared to the other construction firms and it relies on the poor condition. The safety management system of this firm is better than other firms but does not comply with the safety standards. The mean value of the fourth construction firm is $52.85 \%$, mean value of the fifth construction firm is $53.57 \%$, mean value of the sixth construction firm is $51 \%$, all of these firms have got the poor safety management system, lack of safety training, working in the unsafe condition and lack of technical safety knowledge. The mean values of seventh construction firm is $45 \%$ which is the lowest value as compared to the other construction firms and the final mean value of the eighth construction firms is $48.14 \%$. Hence, the result shows that all the construction firms fail to manage the safety management system in their operations. Besides that, these firms fail to manage the safe workplace environment as well and do not follow the local and international safety rules and regulation. After assessing the scale, it was observed that the safety performance of all the construction firms was poor due to absence of safety management system, because all the construction firms were unable to meet the standard or average safety criteria. The basic reasons of poor safety management system in the construction industries were lack of safety awareness, absence of safety management system, carelessness of top management towards implementation of safety, lack of use of safety standards and procedures, absence of a good safety department, absence of qualified safety managers/officers, unqualified employees. It was revealed that the occupational health and safety management of all companies are poor because no concept of safety prevails there. This happens due to the lack of implementation of standards of codes and rules.

The Reliability of the data was calculated with the help of Cronbach's alpha to be 0.980 .

\subsection{Risk Assessment at The Construction Sites:}

Risk assessment is defined as the careful examination of the activities and hazards in the workplace keeping in view, the assessments of risk was performed at work sites with the purpose of checking whether the working conditions are suitable enough or not. Whether a worker is given provisions regarding health and safety or not? In this study, the risk is assessed quantitatively as well as qualitatively by visiting sites. The quantitative assessment was made using $(5 \times 5)$ risk matrix. For doing so, list of hazards was developed. These hazards are those which commonly prevail in all working conditions almost. These hazards are Fall of labor at height, Noise, Dust, Electric shock Welding, cutting of metal sheets, Grinding, Masonry work, Mixture machine operations, Extreme temperature, lifting of steels and tools, Drilling, Scaffolding collapse, Slip and trip, and manual handling. Each hazard was individually inspected and quantified in terms of probability and consequence. By multiplying probability and consequence, the risk factor was estimated. The estimation of each hazard was followed by calculating mean and standard deviation. The mean for each company observation was found to be greater than 16 whereas one company gave the 
mean of 14. These companies mean are compared with the standard action risk level as shown in Table 5. which informs the companies regarding the safety that where they are stand.

Table 4: Risk Action Level

\begin{tabular}{|l|c|}
\hline \multicolumn{1}{|c|}{ Status } & Action Levels \\
\hline Unacceptable & $17-25$ \\
\hline Tolerable & $10-16$ \\
\hline Adequate & $5-9$ \\
\hline Acceptable & $1-4$ \\
\hline
\end{tabular}

Table 5: Risk Assessment at First Construction Site (Mean Risk Value \& Standard Deviation)

\begin{tabular}{|l|c|c|}
\hline \multicolumn{1}{|c|}{ Companies } & $\begin{array}{c}\text { Mean Risk } \\
\text { Value }\end{array}$ & $\begin{array}{c}\text { Standard } \\
\text { Deviation }\end{array}$ \\
\hline Company-1 & 16.13 & 3.64 \\
\hline Company-2 & 19.33 & 3.71 \\
\hline Company-3 & 14.53 & 2.76 \\
\hline Company-4 & 17.67 & 4.16 \\
\hline Company-5 & 16.67 & 3.61 \\
\hline Company-6 & 18.33 & 4 \\
\hline Compnay-7 & 19.67 & 3.51 \\
\hline Company-8 & 19 & 3.87 \\
\hline
\end{tabular}

The mean of the first construction firm is 16.13 as shown in Table 5 which is tolerable means the risk factor is in tolerable condition and can be easily eliminated after taking the certain mitigation measures. The mean of the risk of the second construction firm is 19.33 which is unacceptable and cause serious accident e.g., fatality or loss time injury. The mean of risk of the third construction firm is 14.53 which is also tolerable. The mean of risk of fourth and fifth construction firm is unacceptable. Hence, the average means of the sixth, seventh and eighth construction firms is $18.33,19.66$ and 19 as shown in Tables 5 which is unacceptable and the construction firms may cause the huge economy lost such as fatality, LTI's, delay of orders, penalties.

Most of the observations mean suggests that there were unacceptable conditions regarding safety for workers that increased the occurrence of injuries and accident, whereas the one company was found to be employing a tolerable level of safety which this company somewhat provides the safest environment. From the statistical analysis of both, safety management of the construction site and risk assessment, it is evident that there are poor safety management conditions prevailing in the construction firms that lead to the increased level of risk in the workplace. So, in order to analyze the impact of occupational health and safety on the level of risk involved simple regression was run and Pearson Correlation was also performed.

\subsection{Impact of Occupational Health \& Safety Management on Risk at Construction Site:}

To see the impact of OHSM on Risk prevailing at a construction site, the simple regression was performed in which OHSM was regressed against risk. Besides that, correlation analysis was also performed. The results yielded from regression and correlations are shown in Table 6 and 7.

The results from Table 6 depict that there is a negative relationship between OHSM and Risk prevailing at the construction site. The Pearson correlation coefficient value $(\mathrm{R})$ is -0.969 accompanied with negative sign which implies that OHSM and Risk have a strong negative relationship with each other as we know that the value of $\mathrm{R}$ when becomes greater than 0.5 then the correlation becomes stronger.

Secondly, this negative relationship is also evident from the $\beta$ value (Regression Coefficient) as it is also accompanied with a negative sign, i.e. (-0.393) implying that one percent increase in OHSM causes risk to decrease by 39.3 percent and vice-versa. The $\mathrm{P}$-value is less than 0.05 which says that change in OHSM causes a significant change in Risk.

Table 6: Regression

\begin{tabular}{|l|c|}
\hline Independent Variable & OHSM \\
\hline Regression Coefficient & -0.393 \\
\hline Standard Error & 0.041 \\
\hline & -0.969 \\
Pearson Coefficient & $\mathrm{P}<0.000$ \\
\hline
\end{tabular}

The results from Table 7 depict the regression outcome. The important variable that we see is $\mathrm{R}^{2}$ which possess the value of 0.939 implying that OHSM contributes a variance of $93.9 \%$ in Risk. This implies that OHSM is a major factor that highly affects the risk in the workplace and the company management must ensure an OHSM measure in order to reduce the accidental hazards at the workplace. Besides that, it also implies that there may be other factors that affect risk, for instance, organizational politics, and lack of extrinsic and intrinsic reward, but OHSM is the 
major cause that affects the level of risk in the workplace.

Table 7: Correlation

\begin{tabular}{|l|c|}
\hline \multicolumn{1}{|c|}{ Variables } & Value \\
\hline Multiple Regression & -0.969 \\
\hline R-Square & 0.939 \\
\hline Adjusted R-Square & 0.928 \\
\hline Standard Error & 0.4766 \\
\hline F-Value & $91.584 \quad \mathrm{P}<0.000$ \\
\hline
\end{tabular}

\section{CONCLUSION}

The conclusion of this study is that the construction sites of Karachi need the high level of OHSM in order to make the workplace more secure and reduce the risk level involved in the workplace. The issue of OHSM requires the attention of both management and Government. The management and employees of the construction companies should be provided proper training in order to reduce the hazards involved at workplace and the management should also design the SOPs of their company so that safer working conditions may be ensured.

Besides that, Government is also required to play its role in minimizing the hazards in the sense that it should provide necessary training to the employees and management and also provide the construction companies safer machines so that work environment may be made safer.

\section{REFERENCES}

1. Abel P, Isabel L.N, Rita A.R. Occupational risk assessment in construction industryOverview and reflection, Safety Science (49), (2011): pp 616-624.

2. Allen, K., Reed-Rhoads, T., Terry, R. A., Murphy, T. J., \& Stone, A. D. Coefficient alpha: An engineer's interpretation of test reliability, Journal of Engineering Education, 97(1), (2008): 87-94.

3. Almas H, Wajeeha S, Ghazala Y, Moin U.D G. Comparative assessment of respiratory and other occupational Health effects among elementary workers, International Journal of Occupational Safety and Ergonomics ISSN: 1080-3548 (Print), (2017): 2376-9130.

4. Ashraf A.S, Saeed A. Ergonomic conditions in small manufacturing industry, Science and Technology (6) (2001): pp 60-70.

\section{LIMITATIONS \& FUTURE RESEARCH}

The implementation of occupational health and safety issue is an important to all organizations in all industries, educational institutions, and commercial industries, residential, health care. This research is limited to the construction industry as the construction industry appears to be the growing industry as more and more construction projects are undertaken in Karachi whether in the form of residential projects or commercial projects in both sectors private and government sectors. The other industries in this study have not been considered because of lack of time and other resources required for conducting research. Besides that, this study is also limited in the sense that it has taken few companies into account. Thirdly, the major focus of this study is quantitative. The occupational health and safety issues vary from industry to industry, but the occupational health and safety management system of all industries will be same, because the safety management system helps to make the policy about the OHS issues and take the preventive measures for the protection of workers from workplace hazards.

In future, this study can be extended to other industries or the more depth can be explored by taking more companies into account. Secondly, the qualitative aspect of this study can also be explored by studying the current industrial sector.

5. A. Singupta, D. Bandayopadhyay, C.J van Westen, A. Van der Veen. An evaluation of risk assessment framework for industrial accidents in India, Journal of Loss Prevention in the Process Industries, (2015): pp 1-8.

6. Beatriz F-M, Jose M M-P, Camilo J. Occupational risk management under the OHSAS 18001 standard: analysis of perceptions and attitudes of certified firms, Journal of Cleaner Production 24, (2012): pp 36-47.

7. Book of Successful health and safety management, Health and Safety Executive., (ISBN 97807176 1276 5), (2008): pp 3-98.

8. Buildings codes and contractors, Daily Dawn (17 November, 2005)

9. Cohen, L., Manion, L., Morrison, K.. Research Methods in Education. Routedge Falmer, London, (2005). 
10. George, D., Mallery, P. SPSS for windows step by step: answers to selected exercises, A Simple Guide, (2003): 63.

11. Hassan, C. C., Basha, O. J., \& Hanafi, W. W. Perception of building construction workers towards safety, health and environment, Journal of Engineering Science and technology, (2007): 23- 27

12. Hira A, Zahiruddin K. A Case study of OHS Practices in Steel Rolling Mill, Islamabad, National University of Science \& Technology (NUST), Islamabad Pakistan, 2009.

13. Ishfaq A, Muhammad Z.S, Ahmed U, Muhammad M.N, Mian M.N. Occupational health and safety issues at informal economic segment of Pakistan: A survey of construction sites, International Journal of Occupational Safety and Ergonomics ISSN: 1080-3548 (Print), (2017): 2376-9130.

14. I Raj M.F, Mojtaba K, Man SM, Rostam G, Yadollah H, Alireza S. Evaluation of the Quality of Occupational Health and Safety Management Systems Based on Key Performance Indicators in Certified Organizations, Safety and Health at Work 8, (2017): pp 156-161.

15. John Peter Cooney. Health and Safety in the Construction Industry: A review of procurement, monitoring, cost effectiveness and strategy, MS Thesis, University of Salford Manchester, UK, 2016.

16. Kwasi Yankah. Thesis on Health and Safety management by building contractors in the Ashanti region, Kwame Nkrumah University of Science and Technology, (2012): 145-149

17. Malik, S. A., Iqbal, M. Z., Shaukat, R. A. Z. I. A., \& Yong, J. TQM practices \& organizational performance: evidence from Pakistani SMEs, International Journal of Engineering \& Technology, 10(4), (2010): 2631.

18. Miskeen A.G, Murlidhar N, Awais K, Hussain B.M. An assessment of Occupational health and safety measures and performance of SMEs: An empirical investigation, Safety Science, (2017): 127-133.
19. N.C. Nigam, A.K Maheshwari \& N. P. Rao. Report of IFFCO Aonla unit on Hazard identification and Risk assessment.

20. OHSAS 18001: Guidance document (Occupational health and safety management system, 2007.

21. Rizwan U.F, Farrukh A, S.F.A Rafeeqi. A Case Study on Safety Performance in Construction Industry of Pakistan, First International conference on Construction in developing Countries (ICCIDC-I) Advancing and Integrating Construction Education, Research and Practice NED University of Engineering and Technology, Karachi Pakistan, 2008.

22. Selvarajah, T. Krishnan, Noriah M N. Employer Perception toward Safety and Health on Professionals' Commitment, Ethics and Regulatory Compliance in Malaysia, International Journal of Library Science 5 (2) (2016): pp 21-24.

23. Su Mon K.M, Lynd all S, Mark C, Peter B, Lou G. A method of Identifying Healthbased Benchmarks for Psychological Risks at Work: A Tool for Risk Assessment, Safety Science 93 (2017): pp 143-151.

24. S. Qureshi. The fast growing Megacity Karachi as a frontier of Environmental challenges: Urbanization and contemporary Urbanism issues, Journal of Geography and Regional Planning Vol 3 (11), (2010): pp 306301.

25. S.X. Zeng, Vivian W.Y.T, C.M. Tam. Towards occupational health and safety systems in the construction industry of China, Safety Science 46, (2008): pp 11551168.

26. Tariq Awan. Occupational Health, Safety in Pakistan, Asia Monitor Resource Centre, 2001.

27. Thanwadee C, Supatana T, Suthaporn T. An Investigation of Relationship between Employee's Safety and Productivity, School of Management Technology Thammasat University Thailand. 
28. Tony Boyle. Book of Health and safety risk management, (2015): (ISBN-13: 978-1-13888963-7).

APPENDIX

\section{Research Questionnaire Form}

Name:

Designation:

Gender:

Occupation:

Qualification:

Yearrs of Experience:

1) Do you follow the guidelines of OHSAS 18001?
A. Yes
B. No

2) Have you a Standard Operating Procedure's of OHSAS guidelines?
A. Yes
B. No

3) Do all managers demonstrate their commitment to implement the $\mathrm{OH} \& \mathrm{~S}$ policy in your organization?
A. Yes
B. No

4) Do you review your $\mathrm{OH} \& \mathrm{~S}$ policy and procedure?
A. Yes
B. No

5) Do you follow the local laws and policies of $\mathrm{OH} \& \mathrm{~S}$ such as Sindh Factories Rule 1934/2015?
A. Yes
B. No

6) Do you make an emergency response plan before and start your operation or work in your firm?
A. Yes
B. No

7) In case of emergency do you take corrective actions such as incident investigation \& reporting?
A. Yes
B. No
55

8) Have you planed a level of tolerable risk which is acceptable for your organization/firm?
A. Yes
B. No

9) Have you conducted the risk assessment according to international standard?
A. Yes
B. No

10) Have you arrangement for the welfare of workers?
A. Yes
B. No

11) Have you given the training your worker on $\mathrm{OH} \&$ $\mathrm{S}$ issues such as hazard identification, proper use of PPE'S?
A. Yes
B. No

12) Do you take minimum action against your worker on $\mathrm{OH} \& \mathrm{~S}$ violation?
A. Yes
B. No

13) Do your employees know their health and safety roles and responsibilities?
A. Yes
B. No

14) Are their records of training and evidence of competence?
A. Yes
B. No

15) Are they documented safe system of work where needed?
A. Yes
B. No

16) Are you managing and monitor the safety management system?
A. Ye
B. No

17) Have you collected the data of health and safety at workplace?
A. Yes
B. No

18) Do you conduct the $\mathrm{OH} \& \mathrm{~S}$ induction for visitors or contractors?
A. Yes
B. No

19) Are you conducting the internal or external audit?
A. Yes
B. No

20) Have you been taking the active and reactive evaluations of facilities, equipment, documentation and procedures through safety audits and surveys?
A. Yes
B. No 